\title{
THE STRUCTURE OF THE PATRIOTIC CONSCIOUSNESS OF YOUTH: THE PEDAGOGICAL ASPECT
}

(C) 2019

Pozdnyakova Oksana Konstantinovna, doctor of pedagogical sciences, professor,

corresponding member of Russian Academy of Education, professor of Pedagogy and Psychology Department Samara State University of Social Sciences and Education (Samara, Russian Federation)

Krylova Elena Leonidovna, director

Branch «The Russian Television and Radio Broadcasting Company "Samara"» of The Russian Television and Radio Broadcasting Company (Samara, Russian Federation)

\begin{abstract}
In the framework of the younger generation patriotic education, a pedagogical task of young people's patriotic consciousness development is being actualized. It is substantiated that the solution of this task requires clarification of the content of the notion «young people's patriotic consciousness», the meaning of which is understood when its structure and structural components content are revealed. Interpretations of patriotic consciousness are offered. They are proposed by modern Russian scientists who present it as a systemic development with its own structure. Structural components of the patriotic consciousness of youth are determined: a worldview component (knowledge, ideas, and views), an axiological component (values), a behavioral component (value relations). The possibility and necessity of the separation of these components is proved. The choice of specific concepts, values, and value relationships that form the content of the worldview, axiological, and behavioral components of the patriotic consciousness of youth is substantiated. The content of the ideological component of the patriotic consciousness of young people is revealed; it is formed by the knowledge, ideas, views on the concepts of «patriotism», «love for the Motherland», «Motherland», «small Motherland», «Fatherland», «patriot». In the context of understanding patriotism as a complex value represented through a set of values, it is proved that the content of the axiological component of youth patriotic consciousness is developed by the values of «loyalty», «heroism», «pride in the Fatherland», «duty», «dignity», «interest in the history of the Fatherland», «culture», «love of the country», «courage», «responsibility», «family», «tolerance», «work», «respect», «honor». Valuable attitudes to the family, work, the Fatherland, culture are singled out as developing the content of the behavioral component of young people's patriotic consciousness.

Keywords: consciousness; patriotism; patriotic consciousness; structure; structural components; youth; pedagogical aspect; patriotic education; ideological component; axiological component; behavioral component; knowledge; ideas; attitudes; values; value attitude.
\end{abstract}

$* * *$

УДК 373.2

DOI 10.24411/2309-4370-2019-13314

Статья поступила в редакцию 27.04.2019

\section{НАУЧНО-ПРАКТИЧЕСКИЕ ОСНОВЫ ФОРМИРОВАНИЯ ГОТОВНОСТИ К СОЦИАЛЬНО-БЫТОВОЙ ОРИЕНТАЦИИ СТАРШИХ ДОШКОЛЬНИКОВ В ОРГАНИЗАЦИЯХ ДОПОЛНИТЕЛЬНОГО ОБРАЗОВАНИЯ} (C) 2019

Рябова Наталья Владимировна, доктор педагогических наук, доцент, заведующий кафедрой специальной педагогики и медицинских основ дефектологии

Барцаева Елена Васильевна, старший преподаватель

кафедры специальной педагогики и медицинских основ дефектологии Мордовский государственный педагогический институт имени М.Е. Евсевьева (2. Саранск, Российская Федерация)

\footnotetext{
Аннотация. В данной статье раскрываются научно-практические основы формирования готовности к социально-бытовой ориентации дошкольников в организациях дополнительного образования. На основе анализа психолого-педагогической литературы обосновываются ключевые понятия исследования, рассматриваются возможности организаций дополнительного образования для формирования социально-бытовой деятельности. Понятие «готовность к социально-бытовой ориентации» определяется в логике социокультурного, системного, деятельностного, антропологического подходов и характеризуется как свойство личности, позволяющее проектировать ориентировочную основу социально-бытовой деятельности и реализовывать все ее виды. Рассматривается возможность формирования готовности к социально-бытовой ориентации старших дошкольников в организациях дополнительного образования. В работе «дополнительное образование» рассматривается как инструмент развития социально-значимых качеств личности, обеспечивающих социальную адаптацию к темпам социальных и технологических перемен. Организации дополнительного образования для детей дошкольного возраста обеспечивают единство процессов воспитания, обучения и развития ребенка. В работе представлены результаты проектирования содержательного и процессуального аспектов формирования готовности к социально-бытовой ориентации. Опытно-экспериментальное исследование проводилось на базе Центра продленного дня Мордовского государственного педагогического института имени
} 
М.Е. Евсевьева. В данной организации дополнительного образования создана развивающая образовательная среда, где осуществляется комплексное взаимодействие специалистов (педагог-психолог, учитель-логопед, социальный педагог, учитель-дефектолог), что обеспечивает равные «стартовые» возможности для всех детей дошкольного возраста в аспекте социально-бытовой адаптации. Проведенное исследование показало, что разработанное содержание программы кружка с ориентацией на социально-бытовую направленность, реализованное с дошкольниками в индивидуальной и групповой форме развивающими методами и средствами обучения, обеспечило динамику овладения готовностью к социально-бытовой деятельности.

Ключевые слова: социум; быт; ориентация; социально-бытовая ориентация; готовность; структура готовности; готовность к социально-бытовой ориентации; формирование; этапы; дошкольник; формирование готовности к социально-бытовой ориентации старших дошкольников; организации дополнительного образования.

\section{Введение}

В современной реформируемой отечественной системе образования особое внимание уделяется проблеме социализации ребенка. Анализ психологопедагогической литературы (И.Г. Бочарова, Л.Р. Болотина, О.В. Буданова, Н.Д. Ватутина, Л.С. Выготский, И.В. Дубровина, А.Л. Кононко и др.) позволил сделать вывод о том, что данный процесс осуществляется последовательно и планомерно с момента рождения малыша, приобретая особую актуальность в дошкольном возрасте. В этот возрастной период начинает формироваться новый опыт социальных отношений, в игре как ведущем виде деятельности развивается ролевое поведение, усваиваются нормы, правила и ценности, принятые в социуме. Дошкольник начинает самостоятельно познавать окружающую действительность, социальную и бытовую среды, осваивать различные виды социально-бытовой деятельности. Основу данного процесса составляет интегративная характеристика личности - социильно-бытовая ориентация [1].

Актуальность проблемы становления и развития готовности к социально-бытовой ориентации дошкольников предопределяется Федеральным государственным образовательным стандартом дошкольного образования (ФГОС ДО), где указана «... необходимость формирования у дошкольников норм и ценностей, принятых в обществе; развития общения и взаимодействия ребенка со взрослыми и сверстниками, формирования готовности к совместной деятельности с ними; формирования уважительного отношения и чувства принадлежности к своей семье и к сообществу детей и взрослых, а также позитивных установок к различным видам труда и творчества, основ безопасного поведения в быту, социуме, природе; формирования первичных представлений о себе, других людях, объектах окружающего мира, о свойствах и отношениях объектов окружающего мира» [2]. Сегодня возможности для формирования готовности к социально-бытовой ориентации у детей дошкольного возраста открываются как для организаций дошкольного, так и дополнительного образования.

Целью нашего исследования стало обоснование ключевых понятий и возможностей формирования готовности к социально-бытовой ориентации старших дошкольников в организациях дополнительного образования.

\section{Результаты}

\section{теоретического исследования}

Понятие «социально-бытовая ориентация» рассматривается нами многоаспектно с позиций следу- ющих подходов: социокультурного (механизм адаптации, обеспечивающий усвоение ребенком социокультурного опыта общественных отношений и позволяющий включаться в окружающую социальнобытовую среду, чувствовать себя в ней комфортно, реагировать адекватно на происходящие изменения); системного (адаптационный механизм - ориентация в социальной среде, формируемый в процессе взаимодействия двух систем («человек» и «социальная среда») и обеспечивающий изучение и освоение окружающей социально-бытовой среды и деятельности); деятельностного (ориентировочная основа социально-бытовой деятельности человека, обеспечивающая общую ориентировку и ориентировку на исполнение, проектирующие результат (конечный образ продукта) и условия ее протекания, выделяя оптимальные способы реализации, уточняя специфические действия и операции, а также порядок их следования; способствующая изучению и обследованию социально-бытовой среды, в которой будет протекать данная деятельность; участвующая в формировании ее ориентировочной основы, системы социально-бытовых знаний, умений и практико-ориентированного опыта); антропологического (средство социализации, обеспечивающее понимание и эмоциональное восприятие доступной части мира, участвующее в деятельности и общении, а также позволяющее ребенку включаться в социальную среду и овладевать различными видами социально-бытовой деятельности). Таким образом, понятие «социально-бытовая ориентация», с позиций социокультурного, системного, деятельностного и антропологического подходов, определяется как механизм социализации (социальной адаптации), ориентировочная основа социально-бытовой деятельности, средство их реализации [3, с. 23]. Ключевое значение в подготовке ребенка к самостоятельной жизнедеятельности в социуме и быту имеет готовность к социильно-бытовой ориентации.

Понятие «готовность» рассматривается исследователями в различных областях науки и практики (А.Л. Денисова, М.И. Дьяченко, Л.А. Кандыбович, Н.Д. Левитов, М.И. Махмутов, О.В. Митасов, С.Г. Новиков, С.Л. Рубинштейн, В.А. Сластенин, Т.М. Теплов, С.Н. Чистякова и др.). Оно характеризуется многоаспектно, а именно: установка (Н.Д. Узнадзе), способность (Б.Г. Ананьев, С.Л. Рубинштейн), отношение (А.В. Веденов), качество (К.К. Платонов, В.И. Ширинский) и единство свойств личности (В.А. Крутецкий, С.М. Лыбин), ситуативное (П.А. Рудник) и психическое состояние (М.И. Дьяченок, Л.А. Кондыбович), личностное образование (Л.В. Григоренко, Л.Д. Кондрашова, В.А. Сластенин). Понятие «готов- 
ность» рассматривается нами в двух аспектах: вопервых, как состояние (отражает сущность задачи, принятой к решению, а также условия ее выполнения, требующие сформированности определенных знаний и умений); во-вторых, как качество личности (связано с интеллектуальной сферой человека, его эмоционально-волевыми характеристиками, потребностями и мотивами участия в предстоящей работе). Таким образом, «готовность к социально-бытовой ориентации» определяется нами как свойство личности, обеспечивающее ориентировочную основу и выполнение различных видов социально-бытовой деятельности [4, с. 100; 5]. С учетом научных трудов Б.Г. Ананьева, М.И. Дьяченко, Л.А. Кандыбович, Д.Н. Узнадзе структура готовности к социально-бытовой ориентации представлена такими компонентами, как личностный, когнитивный и деятельностный.

Содержательный аспект указанных компонентов структуры готовности соотносится с психолого-педагогическими особенностями детей старшего дошкольного возраста. Анализ работ ученых (Л.С. Выготский [6], А.Н. Леонтьев [7], Д.Б. Эльконин [8], С.Л. Рубинштейн [9] и др.) свидетельствует, что характеристика основных возрастных новообразований (становление основных личностных механизмов и образований, нравственных ценностей и установок, социально-психологических особенностей в общении с людьми, развиваются мотивационно-потребностная и эмоциональная сферы, формируется самосознание), специфика социальной ситуации развития (ребенок - взрослый), особенности ведущей деятельности (игровая) дают возможность рассматривать старший дошкольный возраст как сенситивный период формирования готовности к социально-бытовой ориентации. Содержательное наполнение структурных компонентов готовности к социально-бытовой ориентации может быть представлено следующим образом: личностный компонент включает ценностные ориентации; мотивационную направленность; эмоциональное благополучие; интегративные качества личности, обеспечивающие становление и развитие готовности к социально-бытовой ориентации [10]; когнитивный компонент включает элементарные представления о себе и об окружающем мире; элементарные социокультурные представления; элементарные представления о социально-бытовой деятельности; элементарные представления о нормах и правилах поведения в социуме [11]; деятельностный компонент включает общеинтеллектуальные; общетрудовые; социально-бытовые; коммуникативные умения [12].

Далее остановимся на проектировании процесса формирования готовности к социально-бытовой ориентации дошкольников в условиях дополнительного образования. В педагогике понятие «формирование» определяется как процесс развития и становления личности под влиянием внешних и внутренних факторов, подразумевает некую целостность личности, достижение уровня зрелости, устойчивости (Ю.К. Бабанский, А.С. Белкин, В.И. Загвязинский, М.Н. Скаткин). В.А. Сластенин понятие «формирование» рассматривает как цель психолого-педагогического процесса, который заключается в создании и обеспе- чении оптимальных условий для приобретения субъектом тех или иных психологических качеств посредством собственной деятельности [13]. В нашем исследовании «формирование готовности к социально-бытовой ориентации» определяется как целенаправленный процесс, обеспечивающий развитие интереса и мотивации к социально-бытовой деятельности, осознания её значимости, формирование личностных качеств, социально-бытовых знаний и умений, накопление опыта практико-ориентированной деятельности [14; 4].

Нами выделены этапы процесса формирования готовности к социально-бытовой ориентации: развитие интереса и мотивации к социально-бытовой деятельности (интересы и мотивы являются гарантами формирования познавательной активности и актуализации познавательных мотивов и, как следствие, приобретения знаний, необходимых для успешной деятельности личности в последующей жизни; мотив обеспечивает удовлетворение потребностей человека, побуждая его к деятельности; предопределяет ее направление, определяет объект; обеспечивает выбор средств достижения цели путем понимания причины выполнения своих действий и поступков; мотивация связана с интересами и направленностью личности; необходимостью адаптации к новой жизненной ситуации); осознание значимости сочиально-бытовой ориентации (на этом этапе необходимо сформировать ориентировочную основу деятельности путем понимания конечной и промежуточных целей, постановки задач, выбора оптимальных условий протекания, что составляет теоретическую сторону деятельности; ориентировочная основа деятельности обеспечивает эффективную реализацию ее практической составляющей, направленной непосредственно на преобразование объектов и получение результата); формирование личностнозначимых качеств, сочиально-бытовых знаний $и$ умений, практико-ориентированного опьта деятельности (на этом этапе необходимо формировать личностно-значимые качества, позволяющие успешно адаптироваться в обществе; знания, позволяющие ребенку включиться в окружающую социально-бытовую среду; общетрудовые и социально-бытовые умения, обеспечивающие накопление опыта практико-ориентированной деятельности; успешность реализации данного этапа обеспечивается применением полученных знаний, умений и опыта в повседневной жизнедеятельности) [1].

Специфика формирования готовности к социально-бытовой ориентации определяется тем, что данный процесс осуществляется в условиях, во-первых, максимально приближенных к реальной социальнобытовой среде, во-вторых, в организациях дополнительного образования.

Понятие «дополнительное образование детей» раскрывается многоаспектно, а именно: самостоятельная образовательная сфера (В.В. Абраухова, А.Г. Асмолов, Г.П. Буданова, В.А. Горский, Г.И. Гузева и др.); часть общей системы образования (В.П.Голованов, А.В. Скачков, Н.И. Фуникова, Л.Н. Ходунова; А.И. Щетинская и др.); процесс (В.А. Березина; А.К. Бруднов, Е.Б. Евладова, Л.А. Николаева и др.); 
Рябова Н.В., Барцаева Е.В.

пространство (А.Я. Журкина, Л.Г. Логинова, Л.Ю. Ляшко, Н.А. Нефедова, В.В. Усанов и др.), система (А.В. Егорова, Е.В. Смольников, М.И. Чеков, О.Г. Тавстуха и др.). Таким образом, в современном образовательном пространстве понятие «дополнительное образование» характеризуется как инструмент формирования ценностей, мировоззрения, гражданской идентичности подрастающего поколения, адаптивности к темпам социальных и технологических перемен. Дополнительное образование прибредает актуальность и для развития детей дошкольного возраста, являясь базой для получения нового социального опыта, фундаментом успешной социализации, помощником для ребенка в становлении и совершенствовании собственной жизненной позиции.

Дополнительное образование понимается как тип образования, обеспечивающий единство процессов воспитания, обучения и развития ребенка. В его основе лежит интерес дошкольника, с ориентацией на который выстраивается вся система образования, а именно: содержание, формы, методы и средства, технологии, а также квалификация педагога. Содержание дополнительных общеразвивающих программ может быть различной направленности, в нашем случае - социально-бытовой. Программы реализуются как по группам, так и индивидуально путем сочетания различных форм обучения, методов, средств и технологий. В исследовании мы исходим из того, что данный тип образования обладает широкими возможностями для подготовки дошкольников к самостоятельной жизнедеятельности, в том числе - социально-бытовой, реализация которой невозможна без сформированной готовности к социально-бытовой ориентации. Путем отбора содержания, форм, методов и средств в условиях дополнительного образования можно выстроить процесс целенаправленного формирования указанной готовности.

Анализ научных трудов Ю.К. Бабанского [15], И.М. Чередова [16] позволил понятие «форма» трактовать как способ существования учебного процесса, оболочка для его внутреннего содержания, обусловленного временем и местом обучения, порядком его существования. Следует отметить, что в дополнительном образовании «форма» - это не просто способ существования учебного процесса, а целостный образовательный процесс развития, воспитания и обучения детей, а также организация образовательной, социально-педагогической, досуговой и других видов деятельности в конкретных условиях. Внешнее выражение содержания в дополнительном образовании определяется направленностью и направлением деятельности, в рамках которых выбираются соответствующие формы. В дополнительном образование организующим началом становится не занятие, а творчество, которое реализуется в различных формax, методах и технологиях. Дошкольники группируются в кружки, секции, студии, клубы, мастерские, лаборатории и другие формы детских образовательных объединений, количественный состав которых определяется психолого-педагогической целесообразностью выполняемой деятельности, а расписание составляется с учетом интересов и возможностей детей.
Важным инструментом формирования готовности к социально-бытовой ориентации старших дошкольников в организациях дополнительного образования выступают методы и средства. В.А. Сластенин, рассматривая категорию «метод» в рамках деятельностного подхода, определяет ее как процессуальную характеристику деятельности, ведущую к достижению поставленной цели путем выполнения рациональных и оптимальных действий в ходе решения конкретных задач [13]. С понятием «метод» связаны понятия «прием» и «средство» обучения (первое рассматривается как часть метода, а второе как отдельные действия субъектов процесса обучения) [13]. Таким образом, формирование личностного, когнитивного и деятельностного компонентов готовности к социально-бытовой ориентации у старших дошкольников может успешно осуществляться в организациях дополнительного образования в ходе трех этапов путем применения различных форм, методов и средств.

\section{Организация опытно-} экспериментального исследования

Опытно-экспериментальная часть нашего исследования выполнена в Центре продленного дня (ЦПД) при Мордовском государственном педагогическом институте имени М.Е. Евсевьева (МГПИ) Республики Мордовия. Директор Центра Н.В. Винокурова поясняет, что дополнительные образовательные услуги оказываются для детей дошкольного и младшего школьного возраста [17]. Работа организуется в группах кратковременного пребывания (для детей, не посещающих детский сад); в группах комплексного развития (для детей, посещающих детский сад). Особое внимание уделяется комплексному развитию дошкольников с ограниченными возможностями здоровья и детей «группы риска», что осуществляется в процессе комплексного психолого-педагогического сопровождения такими специалистами как педагог-психолог, учитель-логопед, социальный педагог, учитель-дефектолог.

Для нашего исследования особое значение имела развивающая образовательная среда Центра, обеспечивающая формирование интереса дошкольников к социально-бытовой деятельности, становление и развитие навыков самообслуживания, общественнополезного труда, представлений о правилах взаимодействия в обществе, этических нормах поведения, что в целом обеспечивает его подготовку к самостоятельной жизнедеятельности, в том числе - социально-бытовой [18]. Работа осуществлялась последовательно в соответствии с основными направлениями деятельности Центра: первоначально проводилась диагностика (с целью исследования уровня сформированности готовности дошкольников к социальнобытовой деятельности), далее проектировалось содержание педагогической деятельности, обеспечивающей расширение представлений об окружающем мире, бытовой сфере, собственной готовности ребенка к реализации социально-бытовой деятельности (с этой целью осуществлялось расширение содержательных аспектов Региональной программы образования детей предшкольного возраста, созданной пе- 
дагогическим коллективом Центра), с учетом разработанного содержания проводилась индивидуальная и групповая работа с дошкольниками в условиях ведущей - игровой - деятельности детей (с целью формирования готовности к социально-бытовой ориентации эффективно применялись игровые, здоровьесберегающие, информационные технологии).

В опытно-экспериментальной работе эффективно применялись групповые занятия с дошкольниками по различным видам организованной деятельности в области «Познание», «Коммуникация», «Чтение художественной литературы», «Безопасность», «Социализация», «Труд», «Здоровье», «Художественное творчество», «Музыка». Большое значение отводилось деятельности кружка «Шаг за шагом», где осуществлялась интеграция речевого, познавательного, экологического, художественно-эстетического развития ребенка. С целью формирования готовности к социально-бытовой ориентации применялись такие методы, как сюжетные и ролевые игры (дошкольники брали на себя различные социальные роли, выполняли игровые действия, соответствующие сюжету социально-бытовой направленности), практические работы, элементы проектного метода, практико-ориентированная деятельность, а также средства - содержание программы кружка «Шаг за шагом», развивающая среда образовательной организации, дидактические пособия и материалы социально-бытовой направленности. Таким образом, в ходе опытно-экспериментального исследования, выполненного на базе ЦПД МГПИ, было апробировано содержание программы кружка «Шаг за шагом», направленное на формирование знаний, умений и опыта социально-бытовой деятельности. В ходе апробации данного содержания применялись индивидуальные и групповые формы работы с дошкольниками, игровые, практико-ориентированные, проектные методы и средства развивающей среды организации дополнительного образования.

\section{Выводы}

Во-первых, в современной социально-экономической ситуации развития общества особое внимание уделяется социальной адаптации подрастающего поколения, включению детей в социально-бытовую среду и деятельность. С этой целью необходимо формирование социально-бытовой ориентации, которая определяется в двух аспектах: как целостная, иерархическая система социально-бытовых потребностей и мотивов, задающая структуру ценностей и субъективных смыслов, специфику отношений с миром и к миру, направленность основных линий поведения; как продукт процесса и результата социализации, гарантирующий формирование свойств человека познавать социальную среду, включаться в нее, осваивать различные виды деятельности. Готовность к социально-бытовой ориентации характеризуется как свойство личности, возникающее в процессе социализации, обеспечивающее познание социальнобытовой среды и деятельности, а также включение в социум и освоение различных видов данной деятельности. Структура представлена личностным, когнитивным и деятельностным компонентами.
Во-вторых, сенситивным периодом становления и развития готовности к социально-бытовой ориентации является старший дошкольный возраст. С ориентацией на возрастные новообразования этого периода, особенности социальной ситуации развития и специфику ведущей деятельности определено содержательное наполнение вышеуказанных компонентов готовности. Широкие возможности для формирования готовности к социально-бытовой ориентации имеют организации дополнительного образования. Сегодня дополнительное образование обеспечивает возможности для развития ребенка с раннего возраст с учетом интересов, индивидуальных особенностей, потребностей и имеющегося потенциала. Здесь происходит активизация мотивационных ресурсов обучающихся, стремление узнавать новое, изучать окружающую среду, социально-бытовую действительность и деятельность, овладевая различными видами ролевого поведения в быту, а в конечном итоге - формируется готовность к социальнобытовой ориентации как ориентировочной основы социально-бытовой деятельности.

В-третьих, формирование готовности к социально-бытовой ориентации реализуется в три этапа: осознание значимости социально-бытовой деятельности, развитие интереса и мотивации к ней, личностных качеств, знаний, умений и практического опыта социально-бытовой направленности. С этой целью необходимо создание в организациях дополнительного образования развивающей среды, обеспечивающей единство процессов воспитания, обучения и развития ребенка. Это возможно через комплексное взаимодействие специалистов (педагог-психолог, учитель-логопед, социальный педагог, учитель-дефектолог), а также проектирование содержательного и процессуального аспектов процесса формирования готовности к социально-бытовой деятельности. Апробированное содержание программы кружка «Шаг за шагом», реализованное с детьми дошкольного возраста в индивидуальной и групповой формах активными методами и средствами обучения, обеспечило значительную динамику продвижения дошкольников в овладении социально-бытовой деятельностью.

\section{Список литературы:}

1. Barcaeva E.V., Ryabova N.V., Zolotkova E.V. Scientific and Methodological Basics of Formation of Preschoolers' Readiness for Social and Personal Orientation // International Journal of Engineering \& Technology. 2018. Vol. 7 (4.38). Р. 54-59.

2. Об утверждении федерального государственного образовательного стандарта дошкольного образования: приказ Министерства образования и науки Российской Федерации от 17 октября 2013 г. № 1155 [Электронный ресурс] // https://www.garant.ru/products/ ipo/prime/doc/70412244.

3. Рябова Н.В. Дидактическая система формирования деятельности педагога по социально-бытовой ориентации учащихся / под науч. ред. Ю.В. Варданян. Саранск: Мордов. гос. пед. ин-т, 2008. 155 с. 
4. Рябова Н.В. Педагогические основы социальнобытовой ориентировки умственно отсталых школьников. Саранск: Мордов. гос. пед. ин-т, 2007. $240 \mathrm{c}$.

5. Ryabova N.V., Parfyonova T.A. Study of Personal and Social Adjustment Ability of the Disabled Pupils // International Education Studies. 2015. Vol. 8, № 5. P. 213-221.

6. Выготский Л.С. Педагогическая психология / под ред. В.В. Давыдова. М.: Педагогика, 1991. 479 с.

7. Леонтьев А.Н. Психологические основы дошкольной игры. М.: Педагогика, 1984. С. 37-47.

8. Эльконин Д.Б. Детская психология. М.: Академия, 2007. 384 с.

9. Рубинштейн С.Л. Основы общей психологии. СПб.: Питер, 2000. 712 с.

10. Барцаева Е.В. Сущность личностного компонента готовности к социально-бытовой ориентации дошкольников // Проблемы современного педагогического образования. Сер.: Педагогика и психология: сб. научных трудов. Вып. 59. Ч. 3. Ялта: РИО ГПА, 2018. С. 67-69.

11. Барцаева Е.В. Содержание когнитивного компонента готовности к социально-бытовой ориентации дошкольников [Электронный ресурс] // Современные научные исследования. Вып. 9: сборник статей участников всерос. конкурса «Лучшая молодежная научная статья - 2018», проведенного АНО ДПО «МЦИТО», г. Киров (август 2017 - май 2018 года). Киров: Изд-во МЦИТО, 2018.

12. Барцаева Е.В., Демина М.А., Харлампова А.С. К проблеме содержания деятельностного компонента готовности к социально-бытовой ориентации дошкольников // Вестник образовательного консорциума Среднерусский университет. Серия: Гуманитарные науки. 2018. № 11. С. 12-14.

13. Сластенин В.А., Исаев И.Ф., Шиянов Е.Н. Педагогика / под ред. В.А. Сластенина. 6-е изд., стереотип. М.: Академия, 2007. 576 с.

14. Ezhovkina E.V., Ryabova N.V. Psychological and pedagogic support of children with health limitations // International Education Studies. 2015. Vol. 8, № 4. P. 60-67.

15. Бабанский Ю.К. Оптимизация процесса обучения. М.: Педагогика, 1977. 257 с.

16. Чередов И.М. Формы учебной работы в средней школе. М.: Просвещение, 1988. 157 с.

17. Винокурова Н.В. О возможностях инновационного развития педагогических вузов // Гуманитарные науки и образование. 2011. № 2. С. 14-16.

18. Рябова Н.В., Барцаева Е.В. Особенности сформированности компонентов структуры социальной адаптации дошкольников в организациях дополнительного образования // Гуманитарные науки и образование. 2017. № 3 (31). С. 7-14.

Статья публикуется при поддержке гранта РФФИ «А - Конкурс на лучиие проекты фундаментальных научных исследований» Формирование готовности к социально-бытовой ориентации стариих дочкольников в организациях дополнительного образования (19-013-00508/19).

\section{DEVELOPMENT OF SENIOR PRESCHOOL CHILDREN'S READINESS FOR SOCIAL ORIENTATION IN THE ORGANIZATIONS OF ADDITIONAL EDUCATION}

(C) 2019

Ryabova Natalia Vladimirovna, doctor of pedagogical sciences, associate professor, head of Special Pedagogy and Medical Basics of Defectology Department

Barcaeva Elena Vasilyevna, senior lecturer

of Special Pedagogy and Medical Basics of Defectology Department

Mordovian State Pedagogical Institute named after M.E. Evseviev (Saransk, Russian Federation)

Abstract. This paper considers development of senior preschool children's readiness for social orientation in the organizations of additional education. On the basis of psychological and pedagogical literature analysis the authors substantiate key concepts of the research and consider possibilities of additional education organizations for social activities development. The concept of «readiness for social orientation» is defined in the logic of socio-cultural, systemic, activity, anthropological approaches and is characterized as a property of the individual, allowing to design an indicative basis of social and household activities and implement all its types. In this paper «additional education» is considered as a tool for the development of socially significant qualities of the individual, providing social adaptation to the pace of social and technological change. The organization of additional education for preschool children ensures the unity of the processes of education, training and development of the child. The paper presents the results of designing the substantive and procedural aspects of social orientation readiness development. The experimental research was conducted on the basis of the Extended Day Centre in the Mordovian State Pedagogical Institute named after M.E. Evsevyev. In this organization there is a developing educational environment where a complex interaction of experts (teacher-psychologist, teacher-speech therapist, social teacher, teacher-defectologist) provides equal «starting» opportunities for all children of preschool age in the aspect of social and household adaptation. The study showed that the developed content of the program circle with a focus on social orientation, implemented with preschoolers in the individual and group form of developing methods and means of training, provided the dynamics of mastering the readiness for social activities.

Keywords: society; life; orientation; social orientation; readiness; readiness structure; readiness for social orientation; development; stages; preschooler; development of senior preschoolers' readiness for social orientation; organization of additional education. 